\title{
A cultura agrícola da cana-de-açúcar no Brasil: contribuição ao estudo dos territórios rurais e suas contradições e conflitos
}

\section{Agricultural culture of sugarcane in Brazil: contribution to the study of rural territories and their contradictions and conflicts}

\section{Cultivo agrícola de la caña de azúcar en Brasil: contribución al estudio de los territorios rurales y sus contradicciones y conflictos}

Daniel Féo Castro de Araújo ${ }^{1}$ http://orcid.org/0000-0001-6345-346X Fernando Luiz Araújo Sobrinho ${ }^{2}$ http://orcid.org/0000-0003-1815-8677

\footnotetext{
${ }^{1}$ Doutorando em Geografia - Universidade de Brasília - UnB-Brasil, Mestre em Ciências Sociais - Universidade Federal de Uberlândia - UFU-Brasil E-mail: daniel.feo@gmail.com

${ }^{2}$ Doutor em Geografia - Universidade Federal de Uberlândia - UFU-Brasil, Professor do Departamento de Geografia da Universidade de Brasília - UnB - Brasil. E-mail: flasobrinho@gmail.com
}

\section{Resumo}

Este artigo discute as modificações introduzidas na agricultura brasileira e o modelo de desenvolvimento econômico e político adotado no país desde o início do processo de industrialização na primeira metade do Século XX. Propõe discussão teórica sobre o processo de modernização da agricultura e a dinâmica atual do agronegócio sucroenergético. A metodologia utiliza-se de revisão bibliográfica, bem como a construção de referencial teórico para compreensão e construção de narrativa a respeito do tema. Partindo da análise da cultura agrícola da cana-de-açúcar na formação sócioespacial brasileira e do desenvolvimento agroindustrial canavieiro e as sucessivas crises neste setor, procura-se evidenciar a configuração territorial do setor sucroenergético, seus avanços e retrocessos no cenário nacional e suas relações com o setor de produção de commodities.

Palavras-chave: Modernização da agricultura. Agronegócio Sucroenergético. Commodities.

\begin{abstract}
This article discusses the changes introduced in Brazilian agriculture and the model of economic and political development adopted in the country since the beginning of the industrialization process in the first half of the 20th century. The article proposes a theoretical discussion on the modernization process of agriculture and the current dynamics of sugar-energy agribusiness. The methodology uses a bibliographic review, as well as the construction of a theoretical framework for understanding and building a narrative about the theme. Starting from the analysis of the sugarcane agricultural culture in the Brazilian socio-spatial formation and of the sugarcane agro-industrial development and the successive crises in this sector, we seek to highlight the territorial configuration of the sugar-energy sector, its advances and setbacks in the national scenario and its relations with the commodity production sector.
\end{abstract}

Keywords: Modernization of agriculture. Sucroenergetic Agribusiness. Commodities. 


\section{Resumen}

Este artículo discute los cambios introducidos en la agricultura brasileña y el modelo de desarrollo económico y político adoptado en el país desde el comienzo del proceso de industrialización en la primera mitad del siglo XX. El artículo propone una discusión teórica sobre el proceso de modernización de la agricultura y la dinámica actual de los agronegocios de energía azucarera. La metodología utiliza una revisión bibliográfica, así como la construcción de un marco teórico para comprender y construir una narrativa sobre el tema. Partiendo del análisis de la cultura agrícola de la caña de azúcar en la formación socioespacial brasileña y del desarrollo agroindustrial de la caña de azúcar y las sucesivas crisis en este sector, buscamos resaltar la configuración territorial del sector azucarero, sus avances y retrocesos en el escenario nacional y sus relaciones con El sector de producción de productos básicos.

Palabras clave: Modernización de la agricultura. Agroindustria azucarera. Productos básicos.

Recebido em:20 /02/2019

Aceito para publicação em: 31/03/2020

\section{Introdução}

Desde o século XVI com a introdução da cana-de-açúcar no Brasil, a produção desta cultura agrícola encontra-se em grande parte relacionada às demandas do mercado internacional. O açúcar passou a ganhar importância na economia colonial durante os séculos XVI e XVII, período caracterizado pela historiografia de "Ciclo do Açúcar" (PRADO JÚNIOR, 1963, FURTADO, 2005). Neste período a região Nordeste do Brasil e mais especificamente a Zona da Mata e o Recôncavo Baiano eram os principais polos de atividades vinculados ao cultivo da cana, seguidos por Maranhão, Rio de Janeiro e São Paulo (VIEIRA, 2017).

A plantation canavieira e seu aproveitamento para a produção de açúcar foi uma das primeiras atividades econômicas implantadas por Portugal na colônia brasileira. As primeiras mudas de cana-de-açúcar foram trazidas da Ilha da Madeira (Portugal) por Martim Afonso de Souza, responsável pela instalação do primeiro engenho em São Vicente (hoje São Paulo) no ano de 1532. Contudo, foi no litoral nordestino, sobretudo, Pernambuco e Bahia, os principais produtores canavieiros da colônia, tendo essa atividade baseada ainda no uso da mão de obra escrava, predominantemente africana (ANDRADE, 1986).

A maior proximidade do centro consumidor europeu, o regime de ventos que facilitava a navegação, o fértil solo massapé e as condições climáticas tropicais, bem como a presença de diversos rios que desembocavam no litoral foram condições apontadas como atrativas ao avanço dessa atividade em terras nordestinas (FERLINI, 1998). 
As modificações associadas à produção de cana-de-açúcar, desde a sua implantação enquanto atividade agrícola mercantil de larga escala no século XVI influenciou e transformou as estruturas produtivas do setor e o uso do território pelos sujeitos relacionados a esse tipo de atividade econômica. Pode-se afirmar que a cana-de-açúcar integra a formação territorial e social do país do período colonial à contemporaneidade.

A cana-de-açúcar é cultivada em mais de 100 países em diferentes continentes (América, África, Ásia e Oceania). Em que pese à quantidade de países produtores, apenas 10 países concentram $80 \%$ da produção mundial. (FAO, 2019).

O Brasil durante décadas foi o maior produtor mundial de cana-de-açúcar e derivados, perdendo essa posição no período de 2017 a 2019 para a Índia. FAO (2019). Em que pese à diminuição da produção e da área cultivada a partir de 2017 por motivos relacionados às crises hídricas e a diminuição da importação do açúcar pela China, principal comprador desta commoditie, a produção sucroenergética tem alcançado ganhos de produtividade.

De acordo com dados da Companhia Nacional de Abastecimento CONAB (2020), houve na safra de 2019 um aumento de produtividade média por hectare de 4,9\% em comparação ao ano de 2018. A área plantada diminui 1,35\% entre as safras 2019/ 2018 alcançando 8,5 milhões de hectares. Das 642,7 milhões de toneladas moídas nas usinas brasileiras $65 \%$ são destinados à produção de etanol anidro e hidratado e os 35\% restantes para produção de açúcar. ${ }^{3}$

O setor de produção agrícola de cana-de-açúcar integra a moderna produção agropecuária brasileira destinada à exportação de derivados de cana. A utilização de maquinário e de técnicas de irrigação, controle de pragas e aumento da produtividade coloca esse setor no complexo conjunto de atividades do agrohidronegócio brasileiro. THOMAZ JÚNIOR (2010).

Para Ferreira (2016) deve-se compreender a evolução técnica deste setor a partir da utilização de termos que surgem na medida em que a atividade se expande e complexifica. Até a primeira metade do século XX, o setor denominado canavieiro destinava-se exclusivamente à produção de açúcar e álcool etílico para consumo humano. Com a crise do petróleo na década de 70 e a adoção de política de produção e uso de etanol, biocombustível incorporado à gasolina para redução deste derivado de petróleo passasse a utilizar o termo sucroalcooleiro. As inovações tecnológicas a partir dos anos 70 fizeram com que os rejeitos da produção de açúcar e álcool como o bagaço da cana moída fosse queimado em fornos para produção de energia elétrica transformando o conceito para setor sucroenérgetico.

\footnotetext{
${ }^{3}$ https://www.agrolink.com.br/noticias/cana--aumenta-a-produtividade-e-diminui-area 428320.html acessado em fevereiro de 2020 .
} 
O complexo canavieiro atualmente é um dos principais exemplos de agronegócio, pois possuem a produção agrícola altamente tecnificada, com a presença de insumos, implementos agrícolas, maquinários altamente modernos, além do processamento industrial da cana, com a produção, em suas várias formas, de açúcar (VHP, cristal, refinado K, orgânica), etanol (anidro, hidratado, em gel), energia (pela biomassa da cana: bagaço e palha), levedura, etc.. Além de todas as relações que se antecipam e que finalizam esse sistema, como as relações de circulação, transporte, logística, fomentos, mercado e consumo, enfim, as relações capitalistas e de poder envolvidas nesse processo. FERREIRA (2016, p.58).

De acordo com Santos (2009), com a expansão em larga escala dos canaviais e objetivando o desenvolvimento e controle da produção do açúcar no país, o Estado brasileiro- no início da década de 1930 - criou o Instituto do Açúcar e do Álcool - IAA e determinou cotas de produção da cana-de-açúcar por unidade da federação e por usina. Assim, a produção e o valor dos produtos (açúcar e álcool) passaram a ser regulados pelo IAA.

Foi também pelos desígnios do IAA que o álcool assumiu maior importância no cenário nacional, pois havia a preocupação de assegurar o equilíbrio interno entre as safras anuais de cana e consumo de açúcar, [...] os problemas como prejuízos causados pela especulação sobre os estoques desse produto, além do excesso da exportação poderiam ser contornados com a destinação de uma parte obrigatória da cana à fabricação do álcool (SANTOS, 2009, p.109).

Outro programa fundamental relacionado à política do setor sucroalcooleiro foi o Proálcool, pois deu base para toda a infraestrutura necessária às usinas de produção e beneficiamento de açúcar e álcool e voltou a ganhar evidência, sobretudo, a partir da década de 1970 com a abertura econômica e investimentos direcionados para este segmento, tanto de iniciativa pública como privada. Aos poucos o setor adquiria novos moldes, passando a cana-deaçúcar a ser vista não apenas como recurso para a fabricação do etanol, mas também como importante matéria-prima ao setor energético, dentre outras apropriações pelo capital.

O programa Proálcool foi criado durante o regime militar e tinha como projeto ampliar a produção do álcool como combustível e incentivar o seu consumo nos carros fabricados no Brasil. O projeto foi responsável pela intensificação do cultivo da cana-de-açúcar no país e impulsionou a modernização da indústria por meio do aumento do número de destilarias, permitindo assim o surgimento de novos financiamentos para que fossem implantadas mais unidades produtivas. Com o Proálcool verificou-se um desenvolvimento tecnológico no setor da agroindústria canavieira, passou-se a consumir mais o álcool como combustível no país em detrimento da gasolina (LIMA, 2009). 
O programa teve três etapas, sendo a primeira compreendida entre 1975 e 1979: ao valer-se de infraestrutura, inserindo destilarias anexas às usinas para a produção de álcool anidro como aditivo à gasolina. A segunda etapa, de 1979-1986, tem como mote o incentivo à produção de álcool hidratado que passou a ser prioridade dentro do setor para o consumo de veículos movidos exclusivamente a álcool. A terceira etapa, de 1986 ao final da década de 1990, ficou conhecida como desaceleração e crise do setor devido a uma série de fatores como a estabilização do preço do petróleo no mercado internacional; suspensão de financiamentos e corte de subsídios voltados ao setor promovendo desequilíbrio entre oferta e procura de álcool; priorização do açúcar em detrimento do álcool gerando a desregulamentação do setor e influenciando a ocorrência da liberação de preços e produtos para a livre concorrência.

Atualmente a produção da cana-de-açúcar e seus derivados colocam o Brasil em posição de destaque no mercado internacional. A entrada do capital transnacional está relacionada à consolidação do uso do etanol como fonte alternativa ao combustível fóssil no Brasil e apresenta forte tendência a sua aceitação no mercado internacional a partir da abertura de novos mercados, por exemplo, na União Europeia, Coréia do Sul, Estados Unidos, Japão e Caribe (Unica, 2008). Além disso, o país tem os menores custos de produção entre os principais competidores do mercado internacional e lidera o conhecimento da biotecnologia da cana, juntamente com a Austrália e África do Sul.

Fruto do desenvolvimento tecnológico no setor, o etanol de segunda e terceira geração ${ }^{4}$ e a produção de biopolímeros ${ }^{5}$ (Macedo, 2007; Schenberg, 2010), fizeram com que a agroindústria canavieira passasse a ser denominada de "setor sucroenergético" com o alto nível de investimento tecnológico e diversificação crescente nos últimos anos. A cana tradicional, matéria-prima usada na fabricação de açúcar, teve seu aproveitamento ampliado para a produção do etanol e da bioeletricidade.

Os novos benefícios para desenvolver a produção, articulados ao discurso da crise ambiental e energética, a reestruturação produtiva fundamentada em inovações tecnológicas e normativas, a nova espacialização da produção de açúcar, etanol, e energia, ganham ênfase nas áreas do Cerrado no interior do Brasil, marcam e definem um período de reorganização do setor e do território brasileiro (BACCHI e CALDARELLI, 2015).

\footnotetext{
${ }^{4}$ Os biocombustíveis para transportes podem ser categorizados como de primeira geração, composta de culturas alimentares (trigo, cana-de-açúcar, beterraba e sementes oleaginosas), de segunda geração, composta por materiais lignocelulósicos (palha de cereais, colmos de milho, etc.), e os de terceira geração, composta por algas (McCormick, 2010).

${ }_{5}^{5}$ São materiais biocompatíveis e biodegradáveis que têm por objetivo substituir parcial ou totalmente o uso de plásticos de origem petroquímica (Schenberg, 2010).
} 
As transformações no setor da agroindústria canavieira acontecem desde o começo de 1990, início da desregulamentação do Proálcool, o que acarretou a livre concorrência dos preços em que os agentes do setor buscavam dar uma sobrevida ao programa. Assim, a retomada do crescimento no setor veio com a produção dos biocombustíveis e o etanol brasileiro passou a ser competitivo no mercado mundial.

De maneira especial, na última década, houve grande estímulo à produção de etanol, principalmente pelo surgimento dos veículos bicombustíveis (flex ${ }^{6}$ ) em 2003 e 2004, capazes de utilizar qualquer combinação de gasolina e etanol, o que elevou significativamente a demanda interna por etanol hidratado. Com a elevação do preço do barril de petróleo, a intensificação das discussões sobre o aquecimento global e o papel dos combustíveis fósseis na problemática ambiental gerou-se uma alteração decisiva sobre as perspectivas do setor sucroenergético.

Objetiva-se, portanto neste artigo, problematizar as modificações introduzidas na agricultura brasileira e o modelo de desenvolvimento econômico e político adotado no país desde o início do processo de industrialização na primeira metade do Século XX. O artigo propõe uma revisão teórica sobre o processo de modernização da agricultura e a dinâmica atual do agronegócio sucroenergético.

A metodologia de produção da pesquisa inicia-se com a revisão bibliográfica a respeito do tema, direcionada ao entendimento da dinâmica estudada, bem como a construção de referencial teórico de obras direta e indiretamente relacionadas. O levantamento bibliográfico foi feito por meio de pesquisa em bibliotecas, repositórios digitais e revistas científicas com a referência de livros, dissertações, teses, banco de dados e artigos relacionados ao tema. Para tanto, utilizam-se também dados de levantamentos da produção e da situação econômico-financeira das empresas através de publicações de organismos nacionais e internacionais relacionados ao setor canavieiro, assim como do Censo Agropecuário e de bases do Instituto Brasileiro de Geografia e Estatística (IBGE, 2017).

\section{Da civilização do açúcar ao agronegócio canavieiro no Brasil}

O cultivo e o processamento da cana-de-açúcar permanecem presentes no território brasileiro desde o período colonial, e foi por muito tempo responsável pela manutenção do domínio econômico, político e social desse setor agropecuário no cenário nacional. A atividade canavieira essencialmente destinada à produção do açúcar, valorizada mercadoria ao longo do século XVI, foi o principal artigo de comércio internacional, produzindo grandes ganhos

\footnotetext{
${ }^{6}$ Carros com capacidade de funcionar movidos a álcool e a gasolina, ou com a mistura de ambos. 
econômico aos europeus. De acordo com Simonsen (1969) os portugueses cultivaram primeiramente a cana-de-açúcar nas Ilhas da Madeira e São Tomé e Príncipe desde meados do século XV, tendo introduzido a cultura na colônia brasileira somente a partir de 1532. Até a primeira metade do século XVII, o cultivo, a fabricação e comercialização do açúcar foram as principais atividades econômicas da colônia, quando a atenção da coroa portuguesa deslocou-se para a exploração de ouro em outras partes do território, nos atuais estados de Minas Gerais, Goiás e Mato Grosso.

De acordo com Simonsen (1969, p. 142), um dos primeiros engenhos construídos no território brasileiro foi o de Governador, tendo surgido na capitania de São Vicente em 1532 de propriedade do donatário português Martim Afonso de Sousa, e até o século XIX a produção de cana-de-açúcar concentrou-se principalmente no litoral da região Nordeste, na Zona da Mata dos atuais estados de Pernambuco, Paraíba, Sergipe, Alagoas, Rio Grande do Norte e Bahia. A predominância da produção canavieira na faixa litorânea nordestina deveu-se principalmente às suas características naturais favoráveis à cultura como o clima tropical oceânico com chuvas regulares e altos índices de insolação, bem como o solo massapé de grande fertilidade e à proximidade em relação aos grandes centros consumidores europeus, num momento em que a navegação se processava em difíceis condições. Os engenhos eram implantados estrategicamente junto aos rios, que se constituíam como os principais canais de transporte do açúcar até os portos, de onde partiam as embarcações rumo a Portugal.

A “civilização do açúcar" descrita na literatura clássica brasileira por autores como: Caio Prado Júnior (1963), Gilberto Freyre (2001), Sérgio Buarque de Holanda (1936 e 1961), Darcy Ribeiro (1995) e Manuel Correia de Andrade (1986) formou a organização socioespacial da Região Nordeste do Brasil, a rede urbana inicial do país e uma complexidade de relações no campo brasileiro tanto no Nordeste quanto em outras regiões brasileiras.

Em linhas gerais, a produção canavieira no período colonial tinha no engenho de açúcar a principal estrutura produtiva e no latifúndio monocultor com utilização de mão de obra escrava em larga escala, a principal forma de organização das áreas rurais da Zona da Mata nordestina. Os "senhores de engenho" donatários de vastas extensões de terra eram os representantes do poder econômico e político local, sendo a aristocracia rural de uma sociedade patriarcal e hierarquizada entre distintas classes sociais: dos senhores de engenhos aos escravos, passando pelo clero, homens livres, trabalhadores avulsos, comerciantes e militares.

As invasões holandesa e francesa ao território nordestino (século XVII) foram influenciadas por disputas relacionadas à produção de açúcar tanto na capitania de Pernambuco e 
no Maranhão, (HOLANDA, 1961). Com a reconquista dos territórios, a cultura de cana-de-açúcar foi levada para colônias holandesas e francesas no Caribe concorrendo diretamente com o açúcar produzido no Brasil, o que levou a decadência desta cultura durante séculos.

\section{A criação do Instituto do Açúcar e do Álcool e a primeira reestruturação territorial e produtiva do setor canavieiro}

Entretanto, no decorrer da história a atividade canavieira sofreu diversas mudanças de natureza técnica e político-normativa, sobretudo após 1930. O principal evento neste sentido foi à criação do Instituto do Açúcar e do Álcool - IAA em 1933, e marcou um período de forte regulação do Estado na atividade sucroalcooleira ${ }^{7}$, (FERREIRA, 2016). A criação desse órgão governamental tinha como objetivo proteger e fortalecer o setor no mercado interno e externo através da adoção de medidas de planejamento, controle (preços e ofertas) e estímulos à produção, à distribuição e à comercialização de açúcar e álcool, frente à grande depressão da economia mundial iniciada em 1929.

Entre as atribuições desse órgão podemos enfatizar:

Contribuir com a melhoria das condições da agroindústria açucareira nacional e resolver o excedente da produção de açúcar como fomento do álcool combustível, através da estabilização dos preços do açúcar e da construção de novos equipamentos para as destilarias destinadas a produção do álcool (BRAY, FERREIRA, RUAS, 2000, p.19)

A criação do Instituto do Açúcar e do Álcool destaca à subordinação completa da agricultura à indústria para o fornecimento de insumos e equipamentos, e compra da produção.

O Instituto do Açúcar e do Álcool visava fundamentalmente, além da questão açucareira, o problema da intervenção e controle da economia alcooleira, influenciando desde os preços até a comercialização, assistência técnica e financeira aos usineiros interessados na produção do álcool anidro carburante (BRAY; FERREIRA; RUAS, 2000, p.19-20)

Durante a Segunda Guerra Mundial houve a reconfiguração da ocupação canavieira no território brasileiro, com a formação de novo polo de produção: o interior do estado de São Paulo. Segundo Szmrecsányi \& Moreira (1991), haviam problemas de fornecimento na região Centro-

\footnotetext{
7 Para contextualizar a periodização do setor e suas recentes mudanças, adotamos a expressão "setor sucroalcooleiro" para referenciar a atividade entre 1930 e 2002, e a expressão "setor sucroenergético" de 2003 aos dias atuais.
} 
$\mathrm{Sul}^{8}$ com açúcar proveniente do Nordeste, devido aos riscos de ataques submarinos às embarcações que trafegavam pela costa brasileira. A produção e o processamento da cana-deaçúcar em alguns estados da região permitiram sanar esta dificuldade. As diversas medidas estatais de estímulos ao setor, somadas a várias vantagens com relação às condições climáticas, proximidade com grandes mercados consumidores, maior capacidade financeira para investimentos, parque industrial moderno e diversificado, infraestruturas de transporte e energia relativamente consolidadas foram fatores cruciais que promoveram grande concentração espacial de usinas, principalmente em áreas anteriormente ocupadas pela pecuária extensiva e pelo café no interior do estado de São Paulo (SZMRECSÁNYI, 1979).

Na década de 1950, acontecem as primeiras inovações incidentes com a introdução de novo modelo tecnológico voltado para a produção rural, amparado pela importação através de produção industrial e de insumos.

[...] A modernização da agricultura arquitetada pelo Estado, com intuito de dinamizar a produção agrícola do país, mesmo existindo diversas posições contra essa modernização, esta se iniciou no Sul do Brasil nos anos 1950 e, velozmente, atingiu outras regiões. "Em pouco mais de dez anos de investimentos do governo para modernizar o campo brasileiro, os resultados começaram a aparecer, sobretudo, a produção de commodities" (MATOS, 2011, p. 78).

Desta maneira, no final da década de 1950, o processo de expansão da cultura da cana-deaçúcar avança através de incentivos dados aos setores industriais de bens de produção, como equipamentos, instalações, bens ou serviços necessários para a produção de insumos básicos, e se relacionando diretamente com a concentração de terras para a reprodução em outras regiões brasileiras de um modelo modernizado de produção de commodities, destacando que à terra de cultivo é condição necessária à produção, em paralelo a formação de territórios produtivos aonde a monocultura canavieira predomina e se estabelecem novas e contraditórias relações de trabalho sejam elas precarizadas ou formais.

A reestruturação produtiva engendrada pela cana-de-açúcar é possível através de investimentos de capital nacional e transnacional em articulação com o Estado brasileiro em suas diversas instâncias (União, estados e municípios).

Investimentos que configuram um setor integrado e complexo desde as primeiras indústrias de tratores, pelos maquinários empregados nas usinas, os sistemas de irrigação, caminhões para transporte da produção até as usinas e a distribuição dos derivados, biotecnologia e defensivos

\footnotetext{
${ }^{8}$ Região Centro-Sul é a porção do território brasileiro composta pelas macrorregiões geográficas do IBGE, Sul, Sudeste e Centro-Oeste. Esta regionalização é muito utilizada no setor sucroenergético para diferenciar esta área da região Norte-Nordeste, com base em variáveis como calendário de safra, processo de modernização, entre outros.
} 
agrícolas, dentre outros bens e serviços direta e indiretamente relacionados ao setor canavieiro. Na década de 1960 e ao longo dos anos 1970, a industrialização da agricultura brasileira avança e pode ser considerado o marco de constituição do Complexo Agroindustrial Brasileiro - CAI:

Esse processo caracteriza-se, fundamentalmente, pela implantação, no Brasil, de um setor industrial produtor de bens de produção para a agricultura. Paralelamente, desenvolve-se ou moderniza-se, em escala nacional, um mercado para produtos industrializados de origem agropecuária, dando origem à formação simultânea de um sistema de agroindústrias, em parte dirigido para o mercado interno e em parte voltado para a exportação (DELGADO, 1985, p. 3435).

Em 1965, foi criado o Sistema Nacional de Crédito Rural - SNCR direcionado ao financiamento da agricultura, e funcionava como crédito específico vinculado à utilização de insumos e técnicas pré-determinados pelo Estado dentro da estratégia modernizadora. A viabilização da integração do setor agrícola aos setores industriais a montante e a jusante foi articulada através do crédito rural subsidiado e representado por taxas de juros abaixo das cobradas no mercado, e em muitas vezes negativas. Ao longo da década de 70 , as taxas nominais de juros ficaram sempre abaixo da inflação.

Além da modernização em si mesma, o principal significado da integração da agricultura ao circuito financeiro é mais abrangente do que a simples integração técnica inter setorial, uma vez que implicou na mais completa subordinação da agricultura ao poder regulador da política monetária manejada pelo Estado e colocou o mercado financeiro como o parâmetro básico das tomadas de decisões dos agricultores e empresas operando na agricultura (KAGEYAMA 1987, p 13).

Diante dessa perspectiva de desenvolvimento, Matos (2011, p.92), analisa que:

[...] O Sistema de Crédito Rural - SNCR foi o principal instrumento utilizado para a consolidação da modernização da agropecuária. (...). Ao invés de ser uma política que efetivamente consolidasse o desenvolvimento rural, essa política foi promotora de desigualdades, devido ao seu caráter seletivo. A seletividade ocorreu em dois aspectos: áreas produtivas e produtores. Esteve concentrada, sobretudo, nas regiões Sul e Sudeste e direcionada aos médios e grandes produtores.

O SNCR estabeleceu relações de interesses do capital industrial, do Estado e dos grandes e médios proprietários rurais, resultantes de um processo de modernização da agricultura nacional, mas ocorridos de forma concentrada nos estados do Centro Sul, acarretando a exclusão de outras regiões brasileiras e de grupos sociais, notadamente os pequenos agricultores, comunidades indígenas, quilombolas e campesinas. 
[...] poderoso instrumento fortalecido criado pelo governo militar, o SNCR empenhou-se em fornecer as bases materiais para o crescimento econômico e a "modernização" da agricultura brasileira. Todavia, seletiva e explicitamente voltado para os grandes proprietários de terra, viabilizou a internalização da agricultura aos setores industriais a montante e a jusante. O Estado viabilizou, então, o que se denominou Complexo Agroindustrial CAI (THOMAZ JÚNIOR, 2002, p. 80, grifos do autor).

De fato, tem-se um procedimento de concentração da produção no interior dos estados da Região Centro $\mathrm{Sul}^{9}$, abrangendo entre $10 \%$ e $20 \%$ do total de estabelecimentos rurais, sendo as demais regiões do país e vários estabelecimentos rurais de pequeno porte descapitalizados e excluídos do cenário da agricultura nacional, desempenhando funções periféricas à produção nacional, (FERREIRA, 2016). Dada a superioridade das grandes propriedades com capacidade de abastecer mercados em larga escala tanto dentro como fora do país, surge uma massa de agricultores desterritorializados, excluídos ou precarizados em relação ao mercado de trabalho rural, que residiam e trabalhavam em estabelecimentos rurais de pequeno porte, mas que não conseguem inserção no circuito econômico e acabam por constituir uma força de trabalho excedente.

Nas áreas de ocorrência do bioma Cerrado, a partir da década de 1970 podemos analisar o impacto dessa modernização, segundo Matos (2011, p.116):

[...] a partir da década de 1970, somaram-se esforços do Estado e do capital privado para a expansão da fronteira agrícola para as áreas de Cerrado, com o objetivo de consolidar a agricultura moderna nessas áreas. Os projetos estatais implantados nas áreas de Cerrado tinham como justificativa principal a retirada dessas áreas do atraso econômico e sua integração ao restante do país. As operações do governo tornaram essas áreas modernizadas, urbanizadas e integradas à economia nacional e internacional.

A seguir veremos o Programa Nacional do Álcool (Proálcool), criado em 1975 com o objetivo de fomentar a produção e o consumo do álcool combustível (anidro e hidratado) em meio à crise de desabastecimento da gasolina e do diesel provocado pelo "choque do petróleo" ${ }^{10}$ e seus desdobramentos.

\section{O Programa Nacional do Álcool - Proálcool: o setor canavieiro e as crises do petróleo nos anos 70 .}

\footnotetext{
${ }^{9}$ Minas Gerais, Goiás, Rio de Janeiro, São Paulo, Paraná, Santa Catarina e Rio Grande do Sul.

${ }^{10} \mathrm{O}$ "choque do petróleo" foi uma crise gerada por sucessivas altas nos preços e nos cortes das vendas do petróleo feitos pela Organização dos Países Exportadores do Petróleo (OPEP), muito em função da decorrência de conflitos bélicos no Oriente Médio.
} 
É preciso considerar, a partir dos anos 1970, conjuntos de novas atividades na agricultura se articulam às demandas dos complexos agroindustriais. A convergência entre demanda final e produtores de insumos estabelece relações de produção e consumo específicos para determinados produtos e, dessa forma, estruturam-se diferentes complexos agroindustriais, como o da cana-deaçúcar, da soja, da fruticultura, do algodão, café e da carne, e apresentam dinâmicas diferenciadas ao enfrentar conjunturas distintas ao longo das últimas décadas.

De forma específica, o complexo canavieiro é impactado nos anos 1970 pela retração dos preços do açúcar no mercado internacional e a queda das exportações do produto, situação que se intensifica com a primeira crise do petróleo em 1973, grave ameaça à lucratividade do setor. Diante dessa conjuntura os representantes do setor defenderam um programa de subsídios públicos ao setor sucroalcooleiro que havia se expandido e modernizado, e necessitava ser mais competitivo no mercado internacional para amortizar os investimentos feitos, além disso, as sucessivas altas do preço do petróleo impactavam a produção industrial e agrícola brasileira, inflacionando bens e serviços e diminuindo o poder de compra da população, aumentando a dívida pública e a inflação.

Esse contexto de sucessivas crises $(1967,1973,1979,1980)$ impactava de forma negativa as economias brasileira e mundial tendo reflexos tanto na produção agrícola e industrial quanto no consumo e poder de compra da população. A dependência do petróleo enquanto principal combustível fóssil e não renovável utilizado em larga escala no Brasil e no mundo expressava a situação de dependência dos países consumidores em relação aos países produtores e as empresas transnacionais do petróleo. Nesse momento, a produção nacional de petróleo e gás natural não atendia totalmente o consumo nacional dependendo da importação de países produtores.

Nesse contexto o surgimento do Programa Nacional do Álcool - PROÁLCOOL, programa do governo brasileiro para a utilização do álcool como substituto da gasolina, substituindo parte da importação de petróleo por produção de álcool derivado da cana-de-açúcar, matéria prima renovável e produzida em larga escala no Brasil. O discurso à época era o enfrentamento da crise do petróleo com a produção de um combustível nacional como alternativa energética à crise do petróleo e da produção açucareira nacional numa lógica de forte intervencionismo estatal e disponibilidade de recursos públicos mediante subsídios.

Segundo Guedes, Gallo e Martins (2002), a defesa do Proálcool se pautou na justificativa de representar um programa de energia alternativa capaz de substituir o petróleo importado à época, o país importava cerca de $80 \%$ do petróleo consumido. 
O aumento dos preços do petróleo no mercado internacional onerava a produção brasileira, a balança comercial e aumentavam o endividamento externo. (BRAY, FERREIRA e RUAS, 2000).

De acordo com o seu projeto inicial, as fontes de recursos para o Proálcool seriam $40 \%$ provenientes do Fundo de Mobilização Energética e 60\% do Orçamento Monetário do Governo. O Fundo de Mobilização Energética foi o principal instrumento utilizado pelo governo brasileiro, a partir de 1979, para financiar o Programa de Mobilização Energética, um conjunto de medidas de incentivo à produção de petróleo, carvão mineral, xisto, eletricidade, carvão vegetal e lenha. As fontes de recursos do fundo eram por um lado arrecadações extraordinárias, obtidas pela taxação de derivados de petróleo; e, por outro, receita tributária proveniente da antiga Taxa Rodoviária Única - TRU.

Dessa forma, o programa foi criado pelo governo federal em 14/11/1975, com o objetivo de estimular o desenvolvimento da produção e comercialização de álcool combustível para substituição da gasolina e diminuição da dependência da importação de petróleo e evitar a fuga de divisas. Neste contexto, o PROÁLCOOL intensificou a produção de álcool combustível e substituiu as importações do produto. Para Thomaz Júnior (2002, p. 76):

[...] o Programa foi lançado e estrategicamente construído com o propósito de se produzir internamente uma alternativa energética própria, contrapondo-se à dependência do petróleo, num período de ascensão dos preços internacionais do produto e de queda acentuada das cotações do açúcar.

O desenvolvimento dessa cadeia produtiva também apresentava potencial para gerar novos postos de trabalho e incremento econômico nas regiões produtoras.

Apesar dos preços elevados praticados na época, em 1975, o mercado internacional de petróleo estabilizou e as autoridades governamentais diminuíram o interesse no complexo canavieiro, já que a conjuntura macroeconômica demandava medidas mais urgentes para minimizar o desequilíbrio do balanço internacional de pagamentos e o ataque inflacionário, o que perdurou até 1979, quando a segunda crise do petróleo impulsionou a retomada do Proálcool.

Em um primeiro momento, o álcool foi utilizado em mistura com a gasolina e, a partir de 1979, o álcool hidratado começou a ser vendido em postos de abastecimento. Em contrapartida, as fábricas de veículos iniciavam a produção e comercialização de novos modelos desenvolvidos para funcionarem com o combustível e o governo financiou, a juros subsidiados, a instalação de destilarias.

A tabela 1 mostra a expansão da produção de veículos que utilizavam o álcool combustível no período de 1979 a 1985. Destaca-se a partir de 1982 a ampliação desta produção nas categorias 
carros de passageiros, carros comerciais leves e pesados. A produção de veículos movidos a álcool é resultado direto do Proálcool.

No início da década de 1980, numa tentativa de fortalecer o Proálcool, o governo fixa em 59\% do preço da gasolina o limite máximo para o preço do álcool, além de reduzir o preço final dos carros a álcool em um comparativo com os modelos movidos à gasolina comercializados no período. A produção alcooleira e de automóveis movidos a álcool atingiu um pico de produção e consumo nesse período.

[...] o marco do PROALCOOL pode ser considerado o ano de 1985, pois neste ano atingiu-se o maior percentual de venda de veículos movidos a álcool, com $92,7 \%$ do total de veículos produzidos e comercializados no mercado interno. (BRAY; FERREIRA; RUAS, 2000, p. 78).

Verificou-se dificuldades a integral implementação do Proálcool, em especial os problemas de distribuição e estocagem do álcool hidratado e as deficiências tecnológicas dos motores movidos a álcool. A queda nos preços do petróleo, na década de 1980, acabou tornando o álcool mais caro do que o petróleo. Em 1981 o petróleo custava US\$ 35,00 o barril, enquanto o álcool custaria cerca de US\$80,00/U\$90,00 por barril equivalente, e o programa tornou-se inviável. (BRAY; FERREIRA; RUAS 2000).

Tabela 1- Brasil: Milhares de Unidades de carros vendidos a álcool (1979-1985)

\begin{tabular}{l|c|c|c|c}
\hline Periodo & $\begin{array}{c}\text { Carros de } \\
\text { Passageiros }\end{array}$ & $\begin{array}{c}\text { Carros } \\
\text { comerciais } \\
\text { leves }\end{array}$ & $\begin{array}{c}\text { Carros } \\
\text { comerciais } \\
\text { pesados }\end{array}$ & Total \\
\hline 1979 & 2,3 & 0,8 & 0 & 3,1 \\
\hline 1980 & 226,6 & 14,1 & 0 & 240,7 \\
\hline 1982 & 212,0 & 20,7 & 0,9 & 233,6 \\
\hline 1983 & 539,8 & 40,7 & 2,0 & 582,5 \\
\hline 1984 & 505,2 & 60,7 & 2,6 & 568,5 \\
\hline 1985 & 401,7 & 46,7 & 1,6 & 449,7 \\
\hline TOTAL & $2.016,7$ & 190,6 & 8,2 & $2.215,5$ \\
\hline
\end{tabular}

Fonte: Sociedade dos Produtores de Açúcar e álcool. Anais VI Econoalcool. São Paulo,1986.

Apesar da regulação genérica exercida pelo Estado, a partir do final da década de 1980 e após a extinção do IAA, ocorrida em março de 1990, o complexo canavieiro brasileiro foi submetido a uma progressiva desregulamentação concretizada na liberação da produção e da comercialização. 
Esse cenário marca o fim do Proálcool e a passagem pela autorregulamentação do setor, graças à desregulamentação das atividades sucroalcooleiras nacionais, por parte do Estado. (CARVALHO, 2002, p. 42).

Diante disso, exigiram-se do setor maior diversificação e diferenciações produtivas, além de melhores condições técnicas de seus equipamentos. Essas estratégias foram sendo desenvolvidas ao longo da década, geradoras de profundas reformulações na agroindústria canavieira no Brasil. Na tabela 2, visualiza-se a produção total de álcool e açúcar no período de desregulamentação e liberalização do setor sucroalcooleiro.

Tabela 2- Produção de Álcool e Açúcar no período de Desregulamentação e Liberalização da economia brasileira.

\begin{tabular}{c|c|c|c|c}
\hline SAFRA & $\begin{array}{c}\text { Álcool Total } \\
\text { Bilhões Litros }\end{array}$ & $\begin{array}{c}\text { Variação em } \\
\text { relação 90/91 }\end{array}$ & $\begin{array}{c}\text { Açúcar } \\
\text { Milhões toneladas }\end{array}$ & $\begin{array}{c}\text { Variação em } \\
\text { relação 90/91 }\end{array}$ \\
\hline $1990 / 1991$ & 11,5 & & 7,3 & \\
\hline $1991 / 1992$ & 12,7 & $10,4 \%$ & 8,6 & $17,8 \%$ \\
\hline $1992 / 1993$ & 11,6 & $0,8 \%$ & 9,2 & $26 \%$ \\
\hline $1993 / 1994$ & 11,2 & $-2,6 \%$ & 9,2 & $26 \%$ \\
\hline $1994 / 1995$ & 12,6 & $9,5 \%$ & 11,7 & $60,2 \%$ \\
\hline $1995 / 1996$ & 12,5 & $8,6 \%$ & 12,6 & $72,6 \%$ \\
\hline $1996 / 191997$ & 14,4 & $25,2 \%$ & 13,6 & $86,3 \%$ \\
\hline $1997 / 1998$ & 15,4 & $33,9 \%$ & 14,8 & $102,7 \%$ \\
\hline $1998 / 1999$ & 13,9 & $20,8 \%$ & 17,9 & $145,2 \%$ \\
\hline $1999 / 2000$ & 13,0 & $13 \%$ & 19,3 & $164,3 \%$ \\
\hline $2000 / 2001$ & 10,5 & $-8,6 \%$ & 16,0 & $119,1 \%$ \\
\hline $2001 / 2002$ & 11,4 & $0,8 \%$ & 18,9 & $158,9 \%$ \\
\hline
\end{tabular}

Fonte: ALCOPAR, 2019.

A produção de álcool sofreu algumas oscilações, mas acabou fechando o período praticamente com a mesma produção do início, principalmente em comparação com a produção de açúcar, que apresentou aumento considerável no período analisado. Assim podemos observar a tabela (3), os dados referentes à quantidade das agroindústrias sucroalcooleiras no Brasil que apresentou diminuição em 22\% entre 1990/91 e 2001/02:

Tabela3- Quantidade de agroindústrias sucroalcooleiras no Brasil

\begin{tabular}{c|c}
\hline SAFRA & NÚMERO DE UNIDADES \\
\hline $1990-1991$ & 394 \\
\hline $1997-1998$ & 336 \\
\hline $2001-2002$ & 306 \\
\hline
\end{tabular}

Fonte: BACCARIN (2005). 
Dessa forma, o complexo canavieiro tem verificado um processo de concentração produtiva e de centralização de capital que há muito não se via, e tende a diminuir a heterogeneidade produtiva, propiciando redução do número de unidades e elevação da escala média de produção.

\section{A modernização recente da cultura agrícola da cana-de-açúcar: uma nova reestruturação produtiva e territorial motivado pelo mercado internacional}

No contexto atual, muitas empresas atentam para novas estratégias tecnológicas em nome da sobrevivência setorial e de maior competitividade. A utilização de avançadas tecnologias industriais e novas formas de gestão evidencia a preocupação em reduzir custos e aproveitar os subprodutos derivados da cana-de-açúcar.

No que se refere ao mercado de trabalho, Guedes, Gallo \& Martins (2002) afirmam um dos aspectos de sua dinâmica é determinado pelo processo de mecanização do corte da cana-de-açúcar e da utilização intensa de insumos químicos ao longo da produção, acarretando a diminuição do número de postos de trabalho. Para os que não têm seus postos de trabalho eliminados pelo processo de automação exige-se carga horária intensa, grau elevado de exigência e produtividade, além da expansão dos ganhos condicionados ao desempenho da empresa.

A escolha entre produzir álcool anidro, álcool hidratado e açúcar é uma decisão atualmente tomada pelo setor privado de forma geral considerada como variável em relação aos preços relativos dos produtos. Embora exista um limite individual a essa flexibilidade dada pela capacidade instalada de produção de cada um dos produtores, é mais um fator da dificuldade e adequação da oferta à demanda em ambiente de livre mercado. A decisão sobre a oferta torna-se complexa ao envolver diversos mercados integrados de forma simultânea.

De fato, é possível perceber novas regiões fortemente impactadas em suas atividades produtivas pela expansão do complexo canavieiro, incorporando as inovações produtivas, enquanto observa-se a retração de unidades em regiões tradicionais como o Nordeste, que perdeu participação relativa, conforme destacado na tabela 4 .

Analisando os dados em todo Brasil, entre as safras de 1996/1997 e 1997/1998, ocorre redução de 71 unidades produtoras tanto no Centro Sul e ainda ocorrem retrações substanciais de unidades no período. Porém, o ritmo de decréscimo diminui proporcionalmente entre as safras de 1997/98 para 1999/2000 no Brasil e no Centro Sul, ocorrendo aumento de uma unidade em São Paulo. No Nordeste, apesar de a retração de unidades produtivas diminuírem de 1997/98 para 1999/2000, continua proporcionalmente maior do que nas demais regiões referidas anteriormente. 
ARAÚJO, D, F, C. ARAÚJO SOBRINHO, F. L.

Tabela 4- Unidades agroindustriais sucroalcooleiras no Brasil.

\begin{tabular}{c|c|c|c|c}
\hline Ano & Brasil & Centro-Sul & São Paulo & Nordeste \\
\hline $1991 / 1992$ & ---- & 269 & 137 & ---- \\
\hline $1996 / 1997$ & 411 & 281 & 149 & 130 \\
\hline $1997 / 1998$ & 340 & 235 & 135 & 105 \\
\hline $1998 / 1999$ & ----- & 241 & 139 & ---- \\
\hline $1999 / 2000$ & 332 & 223 & 136 & 87 \\
\hline $2000 / 2001$ & ---- & 230 & 127 & ----- \\
\hline
\end{tabular}

Fonte: VIAN, (2003).

Ao considerar as especificidades do complexo canavieiro no Nordeste ressaltam-se as condições naturais desta região e a proximidade com o mercado europeu beneficiaram o aumento da cultura canavieira e a produção do produto de maior valor na economia brasileira, a partir do final do século XVI, o açúcar. Contudo sua lógica de produção sempre se pautou no conservadorismo do campo empresarial, baixa incorporação de progresso tecnológico e nenhuma preocupação com as condições de trabalho. Os grandes produtores recorreram ao recurso da incorporação de novas terras e de mão de obra abundante e barata, numa dinâmica de produção extensiva e que se perpetua na economia regional.

Carvalho (2002) afirma, que os grupos empresariais resistiram e passaram a concentrar a produção de cana de açúcar e álcool e levaram adiante um processo de modernização do setor, inclusive por meio da introdução de novas unidades industriais nos estados do Centro Sul, conforme mencionado anteriormente. Mas a maioria dos usineiros precisou reduzir o número de unidades para lidar com o processo de mudanças introduzidas a partir dos anos 1990, pautadas na desregulamentação do mercado e na modernização do processo de produção e comercialização dos derivados da cadeia produtiva da cana-de-açúcar.

De acordo com os dados do Instituto de Economia Agrícola (2019), os principais grupos de produtos de exportação do agronegócio brasileiro foram: complexo soja (U\$ 38,71 bilhões), carnes (US\$ 13,40 bilhões), produtos florestais (US\$12,73 bilhões), complexo sucroalcooleiro (US\$ 6,93 bilhões) e café (US\$ 4,35 bilhões). A exportação destes cinco grupos representam $81,7 \%$ das exportações brasileiras. ${ }^{11}$

O Departamento Intersindical de Estatística e Estudos Socioeconômicos - Dieese (2007) mostra em pesquisa que o setor sucroalcooleiro gera com as atividades direta e indiretamente relacionadas ao setor em torno de $\mathrm{R} \$ 40$ bilhões a cada ano, e implica na formação de

\footnotetext{
${ }^{11}$ http://www.iea.agricultura.sp.gov.br/out/index.php acesso em fevereiro de 2020.

V. 4, n.1, 2020 http://periodicos2.uesb.br/index.php/geo
}

Este é um artigo de acesso aberto sob a licença Creative Commons da CC BY 
aproximadamente 2,35\% do PIB nacional, além de empregar mais de 3,6 milhões de trabalhadores diretos e indiretos.

O país constitui-se como o segundo maior produtor e exportador de cana e de açúcar (FAO, 2019) e destaca-se pelo desenvolvimento de tecnologia capaz de utilizar combustível renovável alternativo ao petróleo, colocando o Brasil em destaque tanto no mercado interno como externo. Porém um conjunto de modificações emerge dessas mudanças, inclusive o deslocamento de trabalhadores nordestinos para o Centro Oeste, e interior de São Paulo e Triângulo Mineiro, para onde se deslocam usinas do Nordeste ou são introduzidas novas unidades industriais.

Além disso, para garantir a viabilidade econômica da produção de cana-de-açúcar, os grupos proprietários das usinas de esmagamento e transformação da cana em derivados, intensificam a produção em um raio de $80 \mathrm{~km}$ de distância ao redor das plantas industriais. Os contratos estabelecidos com os meeiros, donos da terra mas que arrendam para a produção das usinas impedem a diversificação da produção agrícola. Cria-se uma paisagem monótona aonde um único produto agrícola domina a paisagem, no caso a cana-de-açúcar.

Um conflito estabelecido pelas usinas sucroalcooleiras é a perda de diversidade de produção agropecuária em detrimento da cana. Em paralelo há também problemas ambientais gerados tanto pela produção de rejeitos como o vinhoto utilizado como insumo agrícola, mas que acaba por infiltrar no solo e lençol freático escoando para os rios e tributários. Apesar de proibida a queima da cana antes da colheita, verifica-se inúmeros incêndios de grande porte nas lavouras desta cultura.

Acredita-se, portanto, que há uma dinamização socioeconômica provinda da atividade sucroenergética, mas essa é altamente concentrada e causa uma codependência social e econômica, devido ao fato de estar focada no segmento canavieiro e não criar redes autônomas a este. Essa dinamização concentrada e altamente dependente acaba por contribuir com um desenvolvimento econômico incompleto, bem como por construir um elo legitimador das contradições socioespaciais e ambientais, fruto do agronegócio sucroenergético. ARAUJO SOBRINHO e FERREIRA, (2019, p.76).

Muitas vezes, mascaradas pelos mitos do progresso e do desenvolvimento econômico, atrelados à lógica do agronegócio, mas que são facilmente verificadas pelas formas espaciais, pelas fragilidades ambientais, sociais e econômicas verificadas e pelas desigualdades materializadas nas regiões produtoras.

\section{Considerações finais}


O modelo do agronegócio canavieiro no Brasil passou por profundas alterações no seu ambiente institucional a partir do início dos anos 1990, as quais ocasionaram impactos importantes na competitividade e na organização dessa cadeia produtiva, bem como na forma de articulação política com o Estado.

Consolida-se no território brasileiro como símbolo de modernidade e progresso, na perspectiva da produtividade e competição, como saída para ampliar a demanda de etanol e desenvolver os territórios, consequentemente, como solução para o desenvolvimento do Brasil.

Contudo, o avanço do agronegócio canavieiro demonstra que este complexo produtivo é um dos agentes principais das tensões e dos conflitos na expansão do capital no campo, transformando a reconfiguração dos territórios rurais.

Deste modo, o modelo de desenvolvimento agrícola efetivado a partir da década de 1970, com a instituição do Proálcool, mostra-se como modelo concentrado nas modificações ocorridas no campo brasileiro com um procedimento de modernização da agricultura; já que, ao mesmo tempo em que permite uma agricultura moderna e com altos índices de produtividade produz graves problemas sociais e ambientais.

Destacamos o acirramento das disputas entre o agronegócio e a agricultura familiar pela legitimidade e consolidação de modelos de desenvolvimento distintos, um direcionado à produção em larga escala para exportação e financeirização da economia global e outro destinado à produção de alimentos de diversas culturas para a soberania alimentar da população nacional, a fixação do homem no campo e a diminuição das desigualdades a partir de práticas agropecuárias inclusivas e de valorização da produção familiar.

A dicotomia entre esses modelos de desenvolvimento agrícola e que se revelam portadores de orientações produtivas distintas, confere ao território papel imprescindível na configuração das relações produtivas de poder, capazes de modificar o direcionamento das políticas públicas e da propriedade da renda da terra e da existência e permanência de populações no campo.

Distante de ser um artigo conclusivo e de caráter definitivo a respeito do tema, destacamos a necessidade de proposição de novas pesquisas sobre o complexo produtivo da cana-de-açúcar e que possam investigar outros elementos caracterizadores dos desdobramentos e impactos da agroindústria canavieira sobre o território brasileiro, colaborando para a reflexão, atualização e compreensão das reestruturações produtivas deste setor e seus desdobramentos no campo brasileiro. 
A cultura agrícola da cana-de-açúcar no Brasil: contribuição ao estudo dos territórios rurais e suas contradições e conflitos

ARAÚJO, D, F, C. ARAÚJO SOBRINHO, F. L.

\section{Referências}

ANDRADE, Manuel Correia de. A terra e o homem no Nordeste: contribuição ao estudo da questão agrária no Nordeste. 5. ed. São Paulo: Atlas, 1986.

ARAUJO SOBRINHO, Fernando Luiz e FERREIRA, Lara Cristine Gomes. A produção canavieira e o mito do progresso: agronegócio e agricultura familiar na microrregião Ceres, Goiás. Brasília, Revista Patry Ter, vol. 2 | n. 1 | abril 2019.

ARAUJO SOBRINHO, Fernando Luiz e PIZARRO, Roberto Eduardo Castillo. A construção do agronegócio na região de planejamento Sudoeste Goiano. Porto Alegre, Campos Neutrais - Revista Latino-Americana de Relações Internacionais Vol. 1, No 2, p. 91-106, Maio- Agosto de 2019.

ARAUJO SOBRINHO, Fernando Luiz e RUFO, Tiago Fernando. Modernização agrícola nos Cerrados piauienses: novas dinâmicas socioespaciais e transformações urbanas em Bom Jesus e Uruçui, Piauí. Revista Equador (UFPI), Vol. 5, № 4 (Edição Especial 03), p.164 - 186, 2018.

ASSOCIAÇÃO DE PRODUTORES DE BIOENERGIA DO ESTADO DO PARANÁ ALCOPAR. Disponível em: http://www.alcopar.org.br/ acesso em 19 de dezembro de 2019.

BACCARIN, J. G. A constituição da nova regulamentação sucroalcooleira. São Paulo: Ed. UNESP, 2005.

BACCHI, Mirian Rumenos Piedade; CALDARELLI, Carlos Eduardo. Impactos socioeconômicos da expansão do setor sucroenergético no Estado de São Paulo, entre 2005 e 2009. Nova Economia, [s.1.], v. 25, n. 1, p.209-224, abr. 2015.

Disponível em: http://www.scielo.br/scielo.php?script=sci_arttext\&pid=S0103-63512015000100209 acesso em: 02 de dezembro de 2019.

BRAY, Sílvio C; FERREIRA, Enéas R; RUAS, Davi G. G. As políticas da agroindústria canavieira e o PROÁLCOOL no Brasil. Marília: Unesp Marília Publicações, 2000.

CARVALHO, C. P. O. Novas estratégias competitivas par ao novo ambiente Institucional: o caso do setor sucroalcooleiro em Alagoas 1990/ 2001. São Paulo: Atlas, 2002.

COMPANHIA NACIONAL DE ABASTECIMENTO CONAB.

Disponível em: https://www.agrolink.com.br/noticias/cana--aumenta-a-produtividade-e-diminui-area 428320.html acesso em 12 de fevereiro de 2020.

DEPARTAMENTO INTERSINDICAL DE ESTATÍSTICA E ESTUDOS SOCIOECONÔMICOS

DIEESE. Desempenho do setor sucroalcooleiro brasileiro e seus trabalhadores. São Paulo, Boletim

Estudos e Pesquisas, DIEESE, 2007.

DELGADO, G. C.; CARDOSO Júnior, J. C. Universalização de direitos sociais no Brasil: a previdência rural nos anos 1990. Brasília, DF: IPEA, 2001.

DELGADO, G. Capital financeiro e agricultura no Brasil: 19651985. Campinas: Ed UNICAMP, 1985.

FAO FOOD AND AGRICULTURE ORGANIZATION OF THE UNITED NATIONS. Food Outlook: biannual report on global food markets. Rome/ Italy, FAO, 2019.

FERREIRA, Lara Cristine Gomes. A paisagem regional da microrregião Ceres (GO) - das colônias agrícolas nacionais ao agronegócio sucroenergético. . Tese de Doutorado apresentado ao PPGEA UnB, 2016.

FERLINI, Vera Lúcia Amaral. A civilização do açúcar. 11 ed. 1 reimp. São Paulo: Ed. Brasiliense, 1998.

V. 4, n.1, 2020 http://periodicos2.uesb.br/index.php/geo

Este é um artigo de acesso aberto sob a licença Creative Commons da CC BY 
A cultura agrícola da cana-de-açúcar no Brasil: contribuição ao estudo dos territórios rurais e suas contradições e conflitos

ARAÚJO, D, F, C. ARAÚJO SOBRINHO, F. L.

FREYRE, Gilberto. Casa Grande e Senzala. Rio de Janeiro, Editora Livros do Brasil, 2001.

FURTADO, Celso. Formação Econômica do Brasil. São Paulo, Companhia Editora Nacional, 2005.

GUALDANI, Carla. Assentamentos da Reforma Agrária em áreas de modernização agrícola: territorialidades, segurança alimentar e acesso à água. . Tese de Doutorado apresentado ao PPGEA UnB, 2019.

GUEDES, S.N.R.; GALLO, Z.; MARTINS, L.A.T.P. Passado, presente e futuro da agroindústria canavieira do Brasil: uma reflexão a partir da perspectiva do desenvolvimento sustentável. São Paulo: Atlas, 2002. p.312-319.

HOLANDA, Sérgio Buarque de. Raízes do Brasil. Rio de Janeiro, Editora José Olympio, 1936.

HOLANDA, Sérgio Buarque de. História Geral da Civilização Brasileira. Rio de Janeiro, Editora Bertrand Brasil, 1961.

IBGE, Instituto Brasileiro de Estatística e Geografia, (2010).

Disponível em: http://www.ibge.gov.br/home/estatistica/indicadores/agropecuaria/lspa/default.shtm acesso em 02 de dezembro de 2019.

IBGE, Censo Agropecuário Brasileiro. Rio de Janeiro, Publicações IBGE, 2017. Disponível em: https://www.ibge.gov.br/estatisticas/economicas/agricultura-e-pecuaria/21814-2017-censoagropecuario.html?=\&t=downloads acesso em 16 de fevereiro de 2020.

INSTITUTO DE ECONOMIA AGRÍCOLA. In: http://www.iea.agricultura.sp.gov.br/out/index.php acesso em 15 de fevereiro de 2020.

KAGEYAMA, Angela A. Modernização, produtividade e emprego na agricultura: uma análise regional. Tese (Doutorado em Economia), UNICAMP, Campinas, 1986.

KAGEYAMA, Angela A et alli. A dinâmica da agricultura brasileira 1965/1985. Campinas, UNICAMP, 1987. (mimeo).

KOHLHEPP, G. Análise da situação da produção de etanol e biodiesel no Brasil. São Paulo, Estudos Avançados, v. 24, n. 68, p. 223-253, 1 jan. 2010.

LAGO, André Aranha Corrêa. Energia Potencial. São Paulo, Revista Brasileira de Bioenergia, 2009.

LIMA, Kelly. Comercialização de etanol terá novas regras. O Estado de São Paulo. São Paulo, edição de 23 dezembro de 2009.

MACEDO, Isaias C.. Situação atual e perspectivas do etanol. Estudos Avançados, [s.l.], v. 21, n. 59, p.157-165, abr. 2007.

Disponível em: http://www.scielo.br/scielo.php?script=sci_arttext\&pid=S0103-40142007000100012 acesso em 02 de dezembro de 2019.

MARCEDO, I. Situação atual e perspectivas do etanol. São Paulo, Estudos Avançados, v. 21, n. 59, 2007.

MATOS, Patrícia F. As tramas do agronegócio nas "terras" do Sudeste Goiano. Tese (Doutorado em Geografia), Instituto de Geografia, Universidade Federal de Uberlândia, Uberlândia, 2011.

MCCORMICK, K. “Communicating bioenergy: a growing challenge”. United States, Biofuels, Bioproducts and Biorefining, 2010.

MIRANDA, José Roberto. História da cana-de-açúcar. Campinas, Komedi, 2008. 
A cultura agrícola da cana-de-açúcar no Brasil: contribuição ao estudo dos territórios rurais e suas contradições e conflitos

ARAÚJO, D, F, C. ARAÚJO SOBRINHO, F. L.

PIZARRO, Roberto Eduardo Castillo. O agronegócio e a produção do espaço na região de planejamento Sudoeste Goiano. Tese de Doutorado apresentado ao PPGEA UnB, 2017.

PRADO JÚNIOR, Caio. História Econômica do Brasil. São Paulo, Editora Braziliense, 1963.

RIBEIRO, Darcy. O povo brasileiro: a formação e o sentido Brasil. São Paulo, Companhia das Letras, 1995.

SANTOS, Joelma Cristina dos. Dos canaviais à "etanolatria": o (re) ordenamento territorial do capital e do trabalho no setor sucroalcooleiro da Microrregião Geográfica de Presidente Prudente - SP. Tese de Doutorado apresentado ao PPGEA da Universidade Federal de Uberlândia, 2009.

SCHENBERG, Ana Clara Guerrini. Biotecnologia e desenvolvimento sustentável. São Paulo, Estudos Avançados, [s.1.], v. 24, n. 70, p.07-17, 2010. Disponível em: http://www.scielo.br/scielo.php?pid=S010340142010000300002\&script=sci_abstract\&tlng=pt Acesso em 02 de dezembro de 2019.

SIMÕES, Antônio José Ferreira. Biocombustíveis: A Experiência Brasileira e o Desafio da Consolidação do Mercado Internacional. In: Biocombustíveis no Brasil: Realidades e Perspectivas. Ministério das Relações Exteriores e PNUD (Org.). Editora Gráfica Ltda., 2007.

SIMONSEN, M. H. Ensaios Sobre Economia e Política Econômica. Rio de Janeiro, Apec, 1969.

SOCIEDADE DOS PRODUTORES DE AÇÚCAR E ÁLCOOL. Anais VI Econoalcool. São Paulo,1986.

SZMRECSÁNYI, Tamás. O planejamento da agroindústria canavieira do Brasil: 1930- 1975. São Paulo, Hucitec, 1979.

SZMRECSÁNYI, Tamás e MOREIRA, Eduardo Pestana. O desenvolvimento da agroindústria canavieira do Brasil desde a Segunda Guerra Mundial. São Paulo, Estudos Avançados [online]. 1991, vol.5, n.11, pp.57-79.

THOMAZ JÚNIOR, A. Por trás dos canaviais, os nós da cana. São Paulo, Annablume/FAPESP, 20

THOMAZ JÚNIOR, A. A classe trabalhadora no Brasil e os limites da teoria - qual o lugar do campesinato e do proletariado? In: FERNANDES, B. M. (Org.). Campesinato e agronegócio na America Latina: a questão agrária atual. São Paulo, Expressão Popular, 2008.

THOMAZ JÚNIOR, A. O agrohidronegócio no centro das disputas territoriais. In: Revista Campo Território. Uberlândia, UFU, v.5, n.10, p. 92-122, ago. 2010.

UNIÃO DA INDÚSTRIA DA CANA-DE-AÇÚCAR (UNICA). APEX e UNICA investem R\$ 16,5 milhões para promover etanol brasileiro. 25 fev. 2008.

Disponível em: https://jornalcana.com.br/apex-e-unica-investem-r-165-mi-para-divulgar-etanol/ Acesso em 11de novembro de 2019.

VIAN, C. E. F. Agroindústria canavieira: estratégias competitivas e modernização. Campinas: Átomo, 2003.

VIEIRA, Carlos Alberto Cordovano. Sentido da colonização e revolução brasileira: crítica de caracterizações do modo de produção colonial. Revista Serviço Social \& Sociedade, São Paulo, Epub, n. 129, p.205-224, ago. 2017. 